International Journal of Life Sciences
Available online at http://sciencescholar.us/journal/index.php/ijls
Vol. 3 No. 3, December 2019, pages: $8 \sim 15$
e-ISSN: 2550-6986, p-ISSN: 2550-6994
https://doi.org/10.29332/ijls.v3n3.357

\title{
Evaluation of Post-Harvest Tomato Practices (Lycopersicum Sculentum)
}

\author{
(1) CrossMark \\ Jimmy Cristhian Loor Jumps a, Gonzalo Rigoberto Menoscal Chilán b, Doris Marlene Sancán Murillo c, \\ Alexander Patricio García Mendoza ${ }^{\mathrm{d}}$
}

Article history: Received 18 May 2019, Accepted: 31 August 2019, Published: 08 November 2019

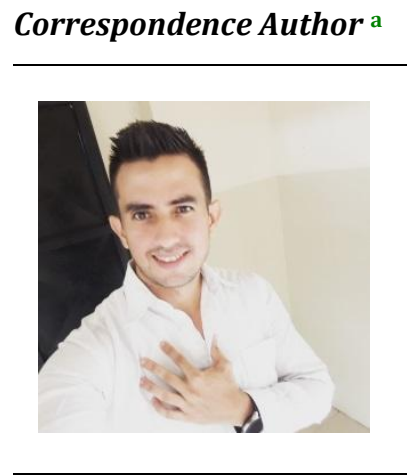

Keywords

commerce;

harvest;

postharvest;

tomato;

transport;

\begin{abstract}
Despite the fact that tomato is the most cultivated vegetable in Portoviejo, there is still a need for change in the production farms with respect to the postharvest handling of the product. The work shows an analysis of the results of inadequate post-harvest management of tomatoes, which was carried out as part of a research teaching work at the Paulo Emilio Macías Higher Technological Institute. The problem is centered on the lack of good postharvest management practices for tomatoes on farms in the Portoviejo canton. The study was applied to 20 producers from 5 populations of rural Portovejenses, whose objective was to determine and quantify post-harvest losses, in the harvest-marketing phase, analyzing the decrease in the quality of the vegetable, due to handling factors, packaging, and transport conditions between farms and the commercialization center. The results obtained show that good post-harvest practices are not carried out and that the producers are unaware of the importance of proper management during collection, transport, and marketing, concluding that it is necessary to create a post-harvest management guide for the cultivation of tomato, to be applied in farms of the Portoviejo canton.
\end{abstract}

e-ISSN: 2550-6986, p-ISSN: 2550-6994C Copyright 2019. The Author. SS Journals Published by Universidad Técnica de Manabí. This is an open-access article under the CC BY-SA 4.0 license (https://creativecommons.org/licenses/by-sa/4.0/) All rights reserved.

\section{Contents}

Abstract 8

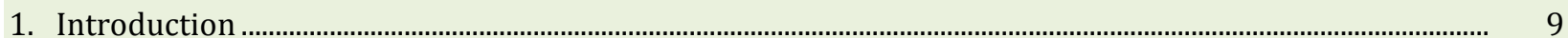

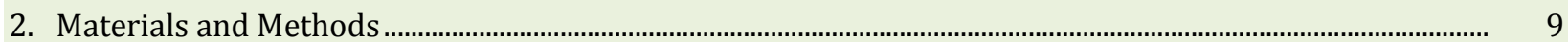

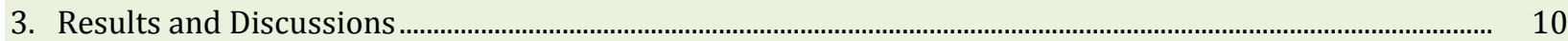

a Instituto Superior Tecnológico Paulo Emilio Macías, Portoviejo, Ecuador

b Instituto Superior Tecnológico Paulo Emilio Macías, Portoviejo, Ecuador

c Instituto Superior Tecnológico Paulo Emilio Macías, Portoviejo, Ecuador

d Instituto Superior Tecnológico Paulo Emilio Macías, Portoviejo, Ecuador 


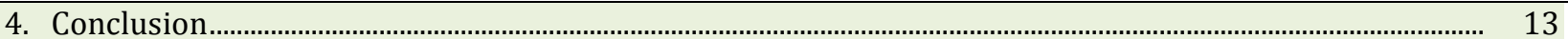

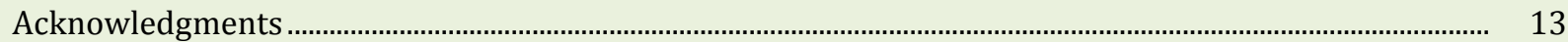

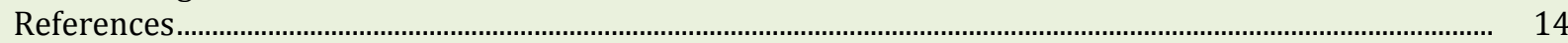

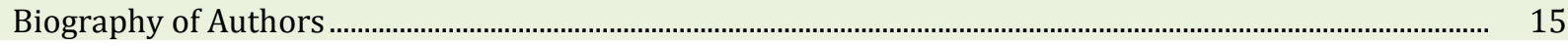

\section{Introduction}

In 2013, FAO estimated that there were 842 million people on earth who were deprived of an adequate food regime, including starving, geographically distributed Asia with 527 million, Sub-Saharan Africa 223 million, Latin America 47 million, North Africa 24 million and Developed Countries 16 million. It was pointed out that the country with the most hungry in India with 214 million (FA0, 2013). From the above, the importance of agriculture can be defined as a food source for humanity at the present time.

In recent years, organic agriculture is discussed as one of the sustainable ways in the production of the individual's food and in the support of the workers' workforce. Organic agriculture is defined as a global production system and one of several methods of sustainable agriculture, which to improve approximately Almost all agricultural ecosystems requires the use of traditional, ancestral and scientific knowledge (UNIDO, 2012).

According to the Food and Agriculture Organization of the United Nations (UNIDO), a good part of agricultural products are exported from developing countries such as Latin America and the Caribbean in which Ecuador is included, destined for developed countries, predominantly Europe and North America, represents $90 \%$ of imports. From this statement, it is well known that Latin American agriculture feeds the population that lives in the main markets and it is necessary that it be taken into consideration (UNIDO, 2012).

Organic production gains ground in the world with natural ecosystems, so man and nature must provoke an efficient system. The novelties that exist because of the excessive use of inputs in conventional agriculture, has caused a loss in biodiversity, notable changes in the health of individuals operating on farms and above all, companies take care of the economic aspect linked to the image of responsibility they project (Benitez et al., 2016).

Vegetables as food are a fundamental part of the human diet, their access to the home implies that processes are carried out from planting to distribution, so that the products are exposed to the environment and handling, increasing the risk of contamination or damage, influencing the reduction of quality with possible effects on the health and food safety of consumers.

Proper post-harvest management constitutes an important phase in the production of vegetables to produce healthy, safe and quality food at the time of consumption, as well as contributing to the reduction of losses, to improve the satisfaction of demand in the markets, Increase competitiveness and finally adapt positively the economy of the producers.

The work is aimed at improving the process associated with the production of tomatoes as a product of mass consumption, for which it focuses on bringing to the farms a tool to strengthen their productive capacity, not only in the post-harvest stage, but in the improvement of the capacities of the producers to assure the quality of the production, as well as in the reduction of losses and in raising the satisfaction of the consumer by means of obtaining a vegetable, which meets the minimum quality requirements.

\section{Materials and Methods}

The research is descriptive, not experimental. It was carried out between June and August of 2019, with the producers whose main activity is tomato production in various rural areas located within the Portoviejo canton. We worked with a sample of eight producing farms, which were intentionally selected, being located in the sectors: El Limón site, via Crucita and Santa Ana.

A survey was applied to determine the extent to which producers apply good post-harvest practices, as a quality assurance strategy, which favors the reduction of losses and better satisfaction of consumer demand. With the design of the survey, we sought to collect information on post-harvest management practices applied

Jumps, J. C. L., Chilán, G. R. M., Murillo, D. M. S., \& Mendoza, A. P. G. (2019). Evaluation of post-harvest tomato practices (lycopersicum sculentum). International Journal of Life Sciences, 3(3), 8-15.

https://doi.org/10.29332/ijls.v3n3.357 
to tomatoes, as well as the level of knowledge that producers have about the benefits achieved with the practices they develop.

Prior to the application of the instrument, a pilot test was carried out with six producers, with the aim of validating it, which identified that there was a logical order in the questions, coherent statements, a good level of understanding and there was no rejection in the questions asked. With this, the instrument that contains the indicators to be measured was validated and ready to be applied.

\section{Results and Discussions}

For many of the tomato growers in the Portoviejo canton, it is difficult for them to correctly apply good postharvest management practices. The research proposes an improvement towards the change of tomato producers, which promotes the improvement of post-harvest practices and their commercialization, in such a way as to allow them a productive and competitive improvement.

The study seeks to know the post-harvest management of tomato producers, not only from harvest, but also transport and marketing to the final consumer, to find a way for the product to arrive in good condition, considering that the time between harvesting and consumption can reach a few weeks and the environment in which it is stored and the way it is managed, can modify the biological and medicinal characteristics of the vegetable (Javanmardi \& Kubota, 2006).

It is important to consider that tomato is also a good source of food for consumers because of its antioxidant content, especially lycopene, so it is important to know the conditions in which they are handled since environmental factors and techniques used in Agriculture can affect its composition (Dumas et al., 2003).

There are problems generated by post-harvest management and that are similar in some parts of the world, such as in Africa, where many of the farm losses are due to inadequate harvest, excessive field heat, the containers used during the harvest, lack of hygiene, or packaging not suitable for products, lack of access roads or inappropriate transportation (Arah et al., 2015; Agustini \& Mataram,2017).

$80 \%$ of tomato producers expressed the non-application of good post-harvest management practices on their farms because they do not have the training, so they are proceeding according to traditional harvesting, transportation and marketing practices until the final consumer.

In Figure 1 it can be seen that $75 \%$ of the producers do not have a solid knowledge about the importance of carrying out adequate post-harvest management to obtain quality tomatoes, reduce the percentage of losses and improve the level of consumer satisfaction.

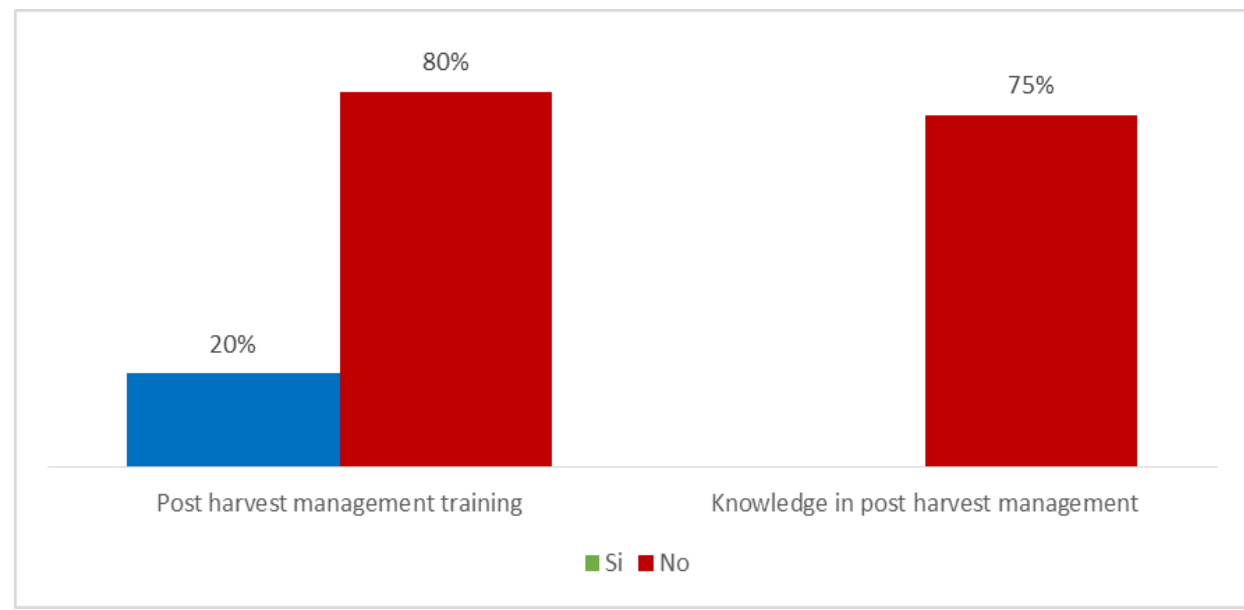

Figure 1. Training received by tomato producers on the harvest and post-harvest of the product Source: Own elaboration with data from surveys carried out on tomato growers

$85 \%$ of tomato growers on the farm consider that projects must be implemented training aimed at improving tomato productivity, improving their post-harvest practices and technologies. As shown in Figure 2. 


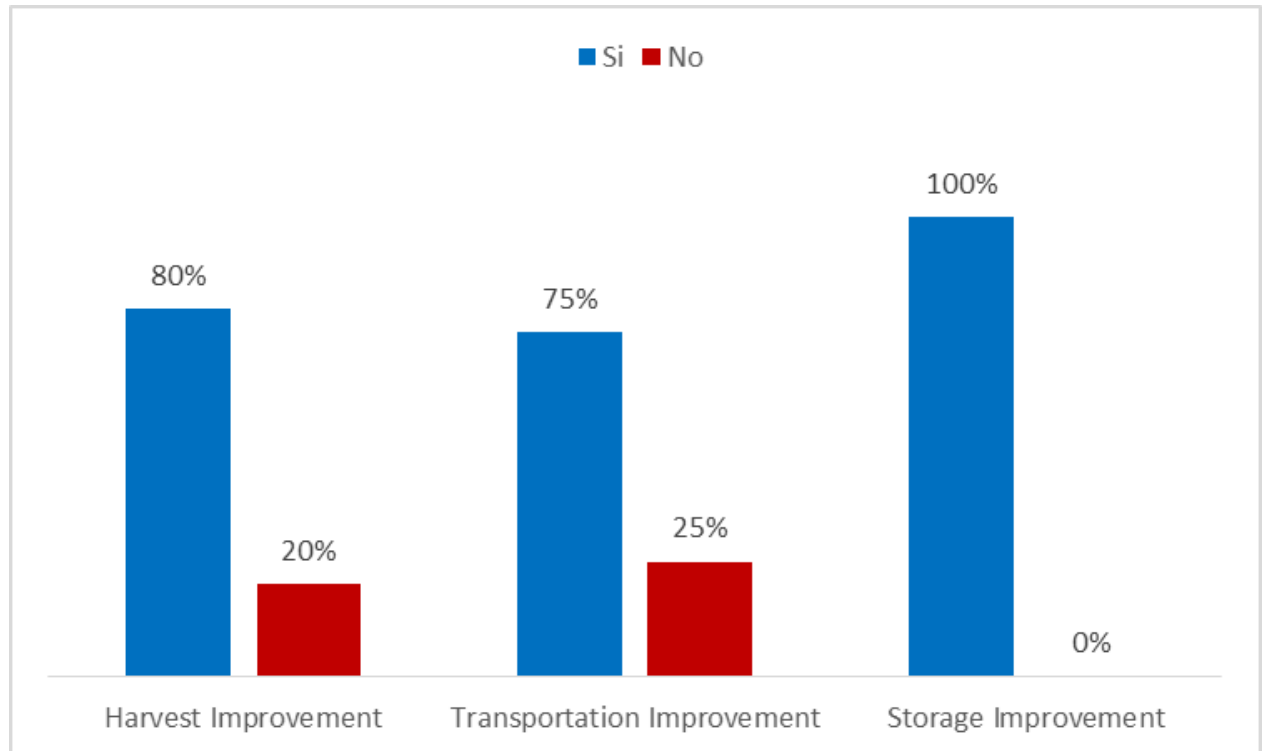

Figure 2. Improvement in harvest, Improvement in Transportation, Improvement in Storage Source: Own elaboration with data from surveys carried out on tomato growers

$90 \%$ of growers believe that projects should be carried out of technological improvement for adequate postharvest management, focused on improving tomato quality, reducing losses and improving customer satisfaction with different post-harvest issues focused on: harvest, storage, transport, and marketing. Figure 3 shows the results obtained with the application of the surveys, taking into account the activities carried out on the farm.

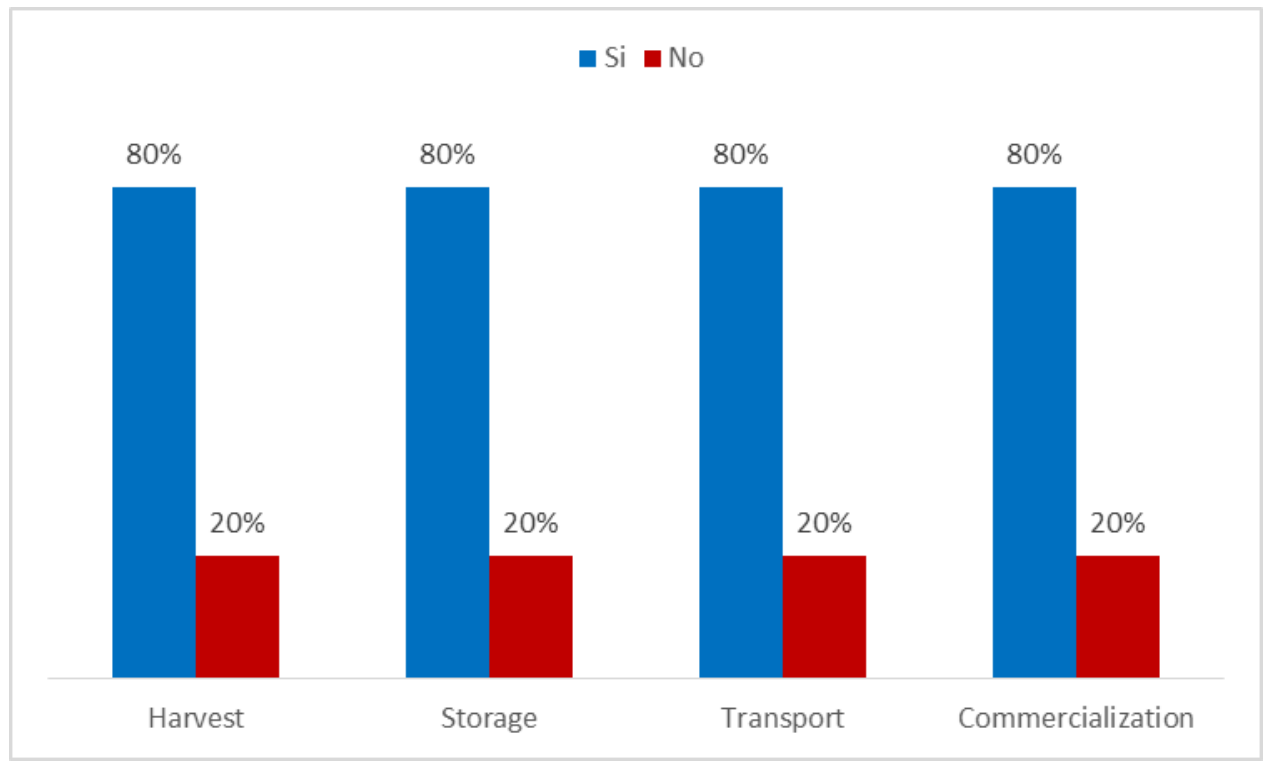

Figure 3. Activities carried out with the tomato on the farm

Source: Own elaboration with data from surveys carried out on tomato producers

The study carried out allowed us to verify the interest that producers have in improving the related aspects of tomato post-harvest, since they consider the need for training on this subject, with the objective that the criteria for post-harvest management be optimized and implemented within the production process.

\footnotetext{
Jumps, J. C. L., Chilán, G. R. M., Murillo, D. M. S., \& Mendoza, A. P. G. (2019). Evaluation of post-harvest tomato practices (lycopersicum sculentum). International Journal of Life Sciences, 3(3), 8-15. 
The study is outlined to give an effective response to the need to improve the actions carried out by tomato farmers on the farm, in relation to the way of handling production from harvest, post-harvest and marketing conditions, in order to improve significantly the quality of production and reduction of losses, on the basis of considering that an appropriate post-harvest management practice, allows to maintain the conditions of freshness of production for as long as possible, however, the form of production must be taken care of, since these practices do not eliminate the problems of the productive phase.

Tomato production is a source of income in most developing countries, however, global losses range by $42 \%$, due to post-harvest losses that reduce crop profitability (Arah et al., 2015). The quality of the postharvest depends to a large extent on the practices that are carried out during the production, being these factors the pruning, the use of fertilizers, the stage of maturity, the irrigation, the selections of cultivars, however, there are Other important factors that should also be considered as temperature, relative humidity, stored gases and the way in which the product is handled (Arah et al., 2015).

In other studies it has been observed that there is a representative deterioration in tomatoes, due to inadequate post-harvest handling and many of the damages are due to post-harvest factors, among which physiological, pathological and mechanical However, it was evidenced that the greater proportion of the damage is due to mechanical causes for all tomato varieties considered in the study, representing the greatest economic loss, followed by pathological damage and finally physiological damage (Adeoye et al., 2009).

It is ensured that the quality of the tomato is affected by a number of factors in the pre-harvest stage and in the post-harvest stage. Regarding the maturity factor on the post-harvest characteristics, it was established that the maturity or the time of harvesting the fruit represents an important factor to preserve its quality (Teka, 2013; Rahimi, 2015).

It has been found that when a reduction of post-harvest losses is made in the tomato industry, the economic yields of the production of the fruit are improved and in the same way, it contributes to improving the quality of the producers, the family and safety food (Sibomana et al., 2016).

The greatest amount of losses in the post-harvest during the supply of fresh tomatoes occurs in the preconsumption stage. It is important to make an adjustment in the tomato production chain to improve yields, benefits, and reduction of waste. Many of the post-harvest losses occur at the level of wholesalers and retailers, the main factors being diseases, the presence of pests, insects, mechanical damage, representing about $20 \%$ of the losses each of these factors (Emana et al., 2017).

During post-harvest management, microbial contamination also plays an important role as a possible risk that can affect the quality of the tomato that is produced. The tomato as a fresh fruit in a natural way, has a protective layer, corresponding to the epidermal layer that protects it against the deterioration of pests, as well as the majority of pathogenic microorganisms, however, this protection is not sufficient and the fruit It can be contaminated during the production process of the crop, harvest, handling, distribution and postharvest, with bacteria and fungi being the main responsible for the deterioration. In this case, the importance of the implementation of good post-harvest management practices for tomatoes is highlighted, which helps to mitigate these contamination risks that put the quality of the product at risk (Bello et al., 2016).

Within post-harvest management practices, there are some alternatives so that some of the microorganisms that may affect production are mitigated, taking into account that there is a tendency towards the use of environmentally friendly products. The use of natural products could be a good alternative for postharvest management. The use of neem oil offers inhibition to the growth of mycelia of the fungus Alternation sp and Botrytis sp. The result is important since it confirms the use of products of natural origin as elements to be used for post-harvest management related to disease control (Ahmed et al., 2017).

Ensuring that tomato farmers on the farm acquire knowledge related to the post-harvest management of tomatoes and that they apply them correctly, helps to lay good foundations for continuous improvement in the production chain in the Portoviejo canton and in the province of Manabí. The losses that may occur in the value chain, require the intervention of each of the actors that are part of it, to conduct training on the postharvest management of perishable products, provide appropriate monitoring and feedback in order to give sustainability and production improvement (Addo et al., 2015). 


\section{Conclusion}

The use of good post-harvest management practices in the Portoviejo canton farms results in the lack of a product of optimum quality and that there are losses of the product, this reality reflects the need to provide training to products in farms, to help reduce post-harvest losses of tomato.

There is an interest in making an improvement in the post-harvest of tomatoes by the producers on the farm, implying the need to develop technical guides for the post-harvest management of the vegetable, which contributes to take the step towards a technological improvement during the harvest, storage, transport and marketing, which ensures greater and better consumer satisfaction.

\section{Acknowledgments}

The author thanks the editor of IJLS for the time, support and advice for the correct completion and publication of the article.

Jumps, J. C. L., Chilán, G. R. M., Murillo, D. M. S., \& Mendoza, A. P. G. (2019). Evaluation of post-harvest tomato practices (lycopersicum sculentum). International Journal of Life Sciences, 3(3), 8-15. 


\section{References}

Addo, J. K., Osei, M. K., Mochiah, M. B., Bonsu, K. O., Choi, H. S., \& Kim, J. G. (2015). Assessment of farmer level postharvest losses along the tomato value chain in three agro-ecological zones of Ghana. International Journal, 2(9), 2311-2476.

Adeoye, I. B., Odeleye, O. M. O., Babalola, S. O., \& Afolayan, S. O. (2009). Economic analysis of tomato losses in Ibadan metropolis, Oyo State, Nigeria. African Journal of Basic and Applied Sciences, 1(5-6), 87-92.

Agustini, N. P., \& Mataram, I. K. A. (2017). Effect induction bio hormone on production and content of nutritional substances on tomato fruit variety cherry small fry and cherry japan. International Research Journal of Engineering, IT \& Scientific Research, 3(3), 103-114.

Ahmed, F. A., Sipes, B. S., \& Alvarez, A. M. (2017). Postharvest diseases of tomato and natural products for disease management. African Journal of Agricultural Research, 12(9), 684-691.

Arah, I. K., Amaglo, H., Kumah, E. K., \& Ofori, H. (2015). Preharvest and postharvest factors affecting the quality and shelf life of harvested tomatoes: a mini review. International Journal of Agronomy, 2015. http://dx.doi.org/10.1155/2015/478041

Arah, I. K., Kumah, E. K., Anku, E. K., \& Amaglo, H. (2015). An overview of post-harvest losses in tomato production in Africa: causes and possible prevention strategies. Journal of Biology, Agriculture and Healthcare, 5(16), 78-88.

Bello, O. B., Ullah, H., Olawuyi, O., \& Adebisi, O. (2016). Microorganisms causing post-harvest tomato (Solanum $\begin{array}{llll}\text { lycopersicum L.) fruit decay in } & \text { Nigeria.Scientia, 13(2), }\end{array}$ http://dx.doi.org/10.15192/PSCP.SA.2016.13.2.9396

Benitez, L. B. C., Castillo, T. P. A., \& Narvaez, R. M. B. (2016). Importance of organic banana production. case: el oro province, ecuador. revista universidad y sociedad, 8(3), 64-71.

Dumas, Y., Dadomo, M., Di Lucca, G., \& Grolier, P. (2003). Effects of environmental factors and agricultural techniques on antioxidantcontent of tomatoes. Journal of the Science of Food and Agriculture, 83(5), 369382. https://doi.org/10.1002/jsfa.1370

Emana, B., Afari-Sefa, V., Nenguwo, N., Ayana, A., Kebede, D., \& Mohammed, H. (2017). Characterization of preand postharvest losses of tomato supply chain in Ethiopia.Agriculture \& Food Security, 6(1), 3. https://doi.org/10.1186/s40066-016-0085-1

FAO. (2013). The importance of food in the world. Accessed September 15, 2019. Available at: http://www.qcom.es/v_portal/imgs/logoPie.png.

Javanmardi, J., \& Kubota, C. (2006). Variation of lycopene, antioxidant activity, total soluble solids and weight loss of tomato during postharvest storage. Postharvest biology and technology, 41(2), 151-155. https://doi.org/10.1016/j.postharvbio.2006.03.008

Rahimi, H. (2015). Social commerce and consumer intention to purchase evidence from popular social networks in Iran. International Research Journal of Management, IT and Social Sciences, 2(3), 11-22.

Sibomana, M. S., Workneh, T. S., \& Audain, K. (2016). A review of postharvest handling and losses in the fresh tomato supply chain: a focus on Sub-Saharan Africa. Food Security, 8(2), 389-404. https://doi.org/10.1007/s12571-016-0562-1

Teka, T. A. (2013). Analysis of the effect of maturity stage on the postharvest biochemical quality characteristics of tomato (Lycopersicon esculentum Mill.) fruit. International Research Journal of Pharmaceutical and Applied Sciences (IRJPAS), 3(5), 180-186.

UNIDO (2012). Overview of the international banana trade, certified by the Food and Agriculture Organization of the United Nations. (2012). Retrieved on September 15, 2012. Retrieved from http://www.fao.org/3/ai0529s/i0529s02.pdf 


\section{Biography of Authors}

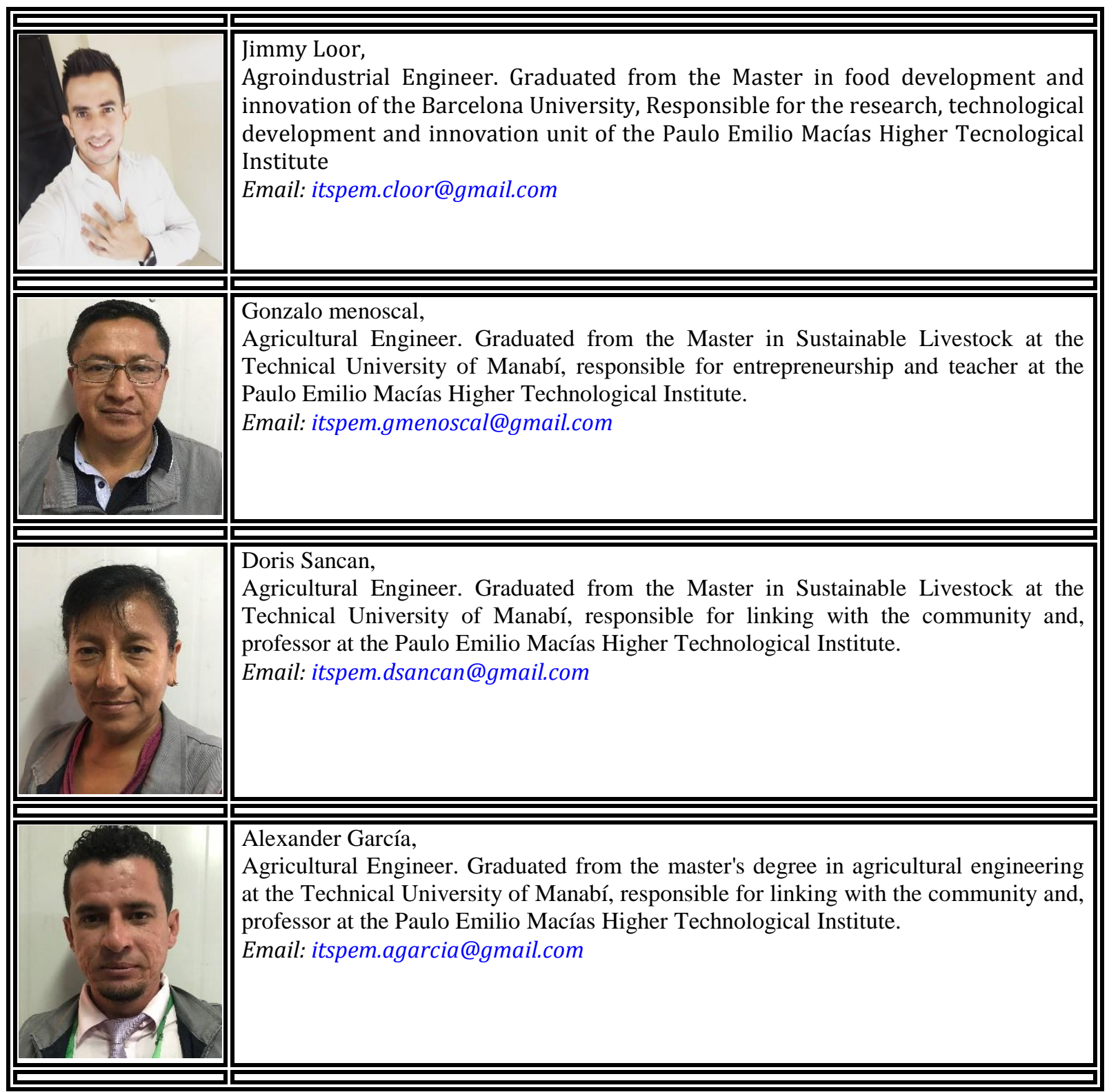

Jumps, J. C. L., Chilán, G. R. M., Murillo, D. M. S., \& Mendoza, A. P. G. (2019). Evaluation of post-harvest tomato practices (lycopersicum sculentum). International Journal of Life Sciences, 3(3), 8-15. 